\title{
Cultivating the Innovation Ability of Middle School Students in Computer Teaching Process
}

\author{
Cai ZhanJun \\ Hebei Oriental University, Dingxing County in Hebei Province, 065001
}

\begin{abstract}
With the continuous improvement of teaching level in colleges and universities, the related problems of computer teaching have also attracted people's attention.Nowadays, in the era of information network, the importance of computer is self-evident, which also improves the specific requirements of computer teaching in colleges and universities. In the process of computer teaching, teachers can not teach for teaching, not only let students master computer knowledge, but also need to cultivate students' innovative ability. In order to truly lay a solid foundation for the development of our computer industry.Therefore, this paper analyzes the cultivation of students' innovative ability in the process of computer teaching in colleges and universities, hoping to provide some reference for relevant teachers.
\end{abstract}

Keywords: university; computer teaching; innovation ability training

\section{Introduction}

Computer-related courses in various colleges and universities includeInternet technology, basic computer teaching and so on. Each specific course content is closely related to innovation.Therefore, in the process of teaching, computer teachers in colleges and universities should not only cultivate students' computer technology, but also consciously enhance their innovative ability so that they can meet the specific requirements of enterprises in the future development.In today's era, the demand for computer talents in enterprises is mainly focused on innovation ability, because only innovation can

https://doi.org/10.47852/bonviewCETR2020010208

This is an open access article published by the BON VIEW PUBLISHING PTE. under the Creative Commons Attributions License. 
progress, only innovation can develop, and only innovation can obtain benefits.However, the traditional computer teaching is old in teaching methods, which is not conducive to improving students' innovative ability. Therefore, this paper analyzes the cultivation measures of students' innovative ability in the process of computer teaching in colleges and universities, which has certain practical significance.

I. The Concept of College Students' Innovative Ability and Present Situation of Cultivation

Innovation ability is not the ability to subvert tradition, especially in the study of computer knowledge. If it can not be based on the previous computer experience, it is difficult for students to really understand computer related technology.However, no matter which kind of technology, it is facing reform in reality. Once practitioners and participants meet the present situation, they may gradually lag behind. Only by cultivating students' innovative ability in teaching process can teachers provide innovative talents for society, keep pace with the times, and create new technologies in the new era.

In the traditional computer teaching process in colleges and universities, teachers take themselves as the main body and do not interact with students reasonably, while students can only listen passively under the podium, and their interest in learning is almost nil. Unable to devote themselves to the study of knowledge.In addition, some teachers in computer teaching completely according to the content of the textbook to let students learn step by step, did not train the students' practical ability, in the long run, students can not innovate on the basis of their own knowledge. It even affects students' enthusiasm for computer learning.

II. The necessity of cultivating students' innovative ability

It is very important for college computer teachers to cultivate students' innovative ability in the course of teaching.Because in today's social development process, computer equipment and modern related to modern industries, and the continuous development of the information age also promotes social development. Computer networks have basically been integrated into people's daily lives. Therefore, in order to better meet the needs of the development of the times, computer teachers in colleges and universities must cultivate their innovative ability and stimulate their innovative thinking on the basis of improving their computer operation ability. Only in this way can we better achieve the teaching goal.

From the point of view of students, learning computer can not only better adapt to the society, but also lay the foundation for future employment. With the development of computer industry, only with innovation ability can we win the top spot in the competitive employment system. Therefore, the cultivation of students' innovative ability is beneficial to the development of students, can improve the ability of students' thinking transformation, and promote the continuous development and progress of computer technology in China.The above mentioned is basically the necessity of cultivating students' innovative ability.

III. Measures for Cultivating the Innovation Ability of Middle School Students in Computer Teaching Process in Colleges and Universities 


\section{A. Innovative Teaching Idea of Computer Teachers in Colleges and Universities}

In order to cultivate students' innovative ability, teachers need to innovate themselves first. If teachers do not have innovative consciousness, then the so-called cultivation of students' innovative ability can only be a formalism.College computer teachers need to constantly update their self-concept, find ways to change students' specific cognition of computer, at the same time clarify their previous teaching concepts, and learn more in their spare time. More understanding of the computer industry related to the frontier information, constantly enrich the understanding of computer, thus changing teaching concepts.

In addition, the school level also needs to strengthen the training of computer teachers in colleges and universities, so that computer teachers can realize the seriousness of the problem. If they can not innovate the teaching idea, they will not be able to achieve the teaching goal.In the process of organizing training, relevant experts should be invited to give lectures in schools, to give lectures to teachers, to improve students' teaching concepts, and to make students innovate through teachers. Moreover, it is necessary to instruct computer teachers to change their previous teaching methods, which can not be mandatory for students to learn, but should guide students to learnLet students play a leading role in the process of learning, take the initiative to learn computer knowledge, develop teaching methods in line with students' own, so as to stimulate students' interest in learning and lay a solid foundation for the cultivation of innovative ability.

Moreover, teachers should pay attention to the problems of students' all-round development in the future, constantly improve the level of computer teaching and integrate the new knowledge and technology in the field of computer into the teaching process, develop students' innovative thinking and improve students' innovative ability.

B. Advanced teaching techniques used by computer teachers in colleges and universities

Computer teaching itself is closely related to computer equipment and technology. If we can not use advanced technology, we can not really improve students' computer ability.In the process of teaching, teachers can use advanced teaching technology to create multimedia teaching atmosphere and create a good teaching environmentIn the course of teaching, teachers should combine theory with practice. After explaining a theoretical knowledge point, they should use multimedia technology to demonstrate it and create a three-dimensional and real scene. In this way, students can better deepen their impression of knowledge points and stimulate students' interest in learning.

In the process of teaching some special contents, teachers also need to use advanced teaching technology.For example, when introducing students to the future development trend of computers, the former teaching method is that teachers use teaching words on the podium to explain boringly. Students can not imagine what future computing opportunities will look like. Even after learning specific knowledge, it is not impressive in the brain.If the teacher can turn the specific course content into dynamic video to show the students, the students can learn more actively, because the video can undoubtedly attract students more than the teacher's single explanation. The video should include 
multimedia technology content, introduce the specific advantages of multimedia technology, and then include more advanced multimedia technology and scientific and technological topics of interest to students, such as hackers.In the process of watching the video, students can use their imagination to reasonably predict the future development direction of computer technology, so that they can better create a good learning atmosphere for students and promote the future development of students. Improve students' innovative ability.

C. Student-oriented teaching

The key to cultivate students' innovative ability lies in the students' teaching as the main body. The education of the new era requires the guidance and inspiration of the students, rather than the mandatory management of the students. The student's individuality thought is the innovation foundation, if can not take the student as the main body to carry on the teaching, will produce the restraint to the student's thought.Students can not learn according to their own ideas, nor can they complete computer operation according to their own ideas, which will not only affect their learning attitude, but also affect the promotion of their innovative ability and the stimulation of their innovative consciousness.

The emphasis of teaching with students as the main body is to create a good teaching atmosphere. When students can actively participate in the teaching of teachers, students will become the main body of learning.In the process of computer teaching, teachers should not only pay attention to the teaching of knowledge, but also learn to interact with students, not to let students listen passively under the podium, but to concentrate their attention. Through interaction with students, students can maintain their concentration and achieve good teaching results.

Furthermore, computer teachers must strengthen their thoughts, deepen their theories, attach importance to the psychological changes of students, so that students can accept the learning content more deeply and act as the main body in the classroom.In reality, many students think that computer knowledge is difficult. If they can not fulfill the teacher's requirements, they may be criticized by teachers, resulting in greater psychological pressure. In the long run, they can not only improve their innovative ability. At the same time, it may lead to students weariness. Therefore, teachers must let students fully express their ideas in teaching, enhance students' self-confidence, maintain a harmonious relationship between equality, mutual assistance and mutual learning, and discuss specific problems with students, so that students can give full play to innovative thinking.

D. Increased proportion of operational content

Although it is more important to cultivate students' innovative ability, teachers must realize that it is difficult for students to improve their innovative ability overnight. Only by continuous training can good learning results be achieved.Therefore, in the process of teaching, in addition to choosing advanced teaching techniques and methods, computer teachers also need to increase the proportion of practical content in the arrangement of curriculum content, and provide more practical opportunities for students. In order to implement the students' ideological innovation into reality, constantly improve their innovative ability, exercise their innovative thinking.For example, you can set up computer- 
related design groups for students to discuss and work together.Moreover, it is also possible to hold related computer competitions, such as video editing competitions, programming competitions, design competitions, and even e-sports competitions, which can not only help students practice computer knowledge, but also broaden their horizons and enable students to learn in entertainment. Progress in a relaxed and pleasant atmosphere.

The school level must also provide good resources for students.For example, it can help students set up computer maintenance team, help students who encounter problems but can not overhaul their computers, and improve their practical operation ability. When necessary, schools need to strengthen cooperation with enterprises, contact relevant social institutions to provide students with better internship opportunities, and lay a solid foundation for their innovative ability.

\section{Conclusion}

To sum up, in the course of teaching, computer teachers in colleges and universities should not only cultivate students' computer technology, but also consciously enhance their innovative ability. So that it can be in the future development more in line with the specific requirements of enterprises ; Teachers should pay attention to the problems of students' all-round development in the future, constantly improve the level of computer teaching and integrate the new knowledge and technology in the field of computer into the teaching process; In the process of teaching, teachers should combine theory with practice, after explaining a theoretical knowledge point, immediately use multimedia technology to demonstrate it; In addition to the need to choose advanced teaching techniques and methods, teachers should also increase the proportion of practical content in the arrangement of curriculum content, and provide more practical opportunities for students.

\section{References}

[1] Ma Huifang. An Analysis of the Path of Cultivating Students' Innovative Ability in Computer Teaching J]. Colleges and Universities Journal of Kaifeng Institute of Culture and Art 40(01):174-175.

[2] Wu Dong, Li Renpu. A Study on Cultivating the Innovation Ability of Middle School Students in Computer Major Course Teaching J]. Colleges and Universities Journal of Qufu normal University (Natural Science Edition)(04):122-124.

[3] Luo Pingjuan. A Study on Cultivating Strategies of College Students'Innovation Ability in Computer Teaching [J]. Computer Products and Circulation ,2018(01):172.

[4] Liu Haiyan. A New Thinking on Cultivating the Practical Innovation Ability of Middle School Students in Computer Teaching J]. Colleges and Universities Chinese Journal of Multimedia and Network Teaching (Electronic Edition)2017(04):380. 